\title{
Applying New Evidence into Practice: A Need for Knowledge Translation
}

\author{
Scot H Simpson
}

W

e are all familiar with the need for evidence to support the choices we make. Whether we are deciding on a restaurant for dinner, which movie to see this weekend, or the best winter tires for our vehicle, we often use information - or evidence- to help us choose. The same need for evidence applies in our professional practice. Indeed, the fundamental principles of evidence-based care encourage us to make good clinical choices by being aware of the best available evidence, determining whether the evidence is trustworthy, and putting the evidence in context by examining the benefits and risks, burden (implications), and costs associated with the choice. ${ }^{1}$ Unfortunately, however, the application of new evidence to help facilitate practice change is less than ideal.

Changing clinical practice is a complex and challenging task, and the well-known gap between evidence that supports change and current practice hampers our ability to provide quality, efficient care to our patients. ${ }^{2-4}$ Simply generating new evidence from a research project, presenting the results at a conference, and publishing in a journal are not enough to change practice. ${ }^{5}$ Instead, there is growing recognition that addressing the gap between evidence and practice will require a process called "knowledge translation". Although there are many definitions of this term, ${ }^{6}$ the most widely accepted is "a dynamic and iterative process that includes the synthesis, dissemination, exchange and ethically sound application of knowledge to improve health, provide more effective health services and products and strengthen the health care system."7 This definition recognizes not only that it is important to produce and disseminate new evidence, but also that a critical element is the appropriate-or ethically soundapplication of knowledge.

Traditionally, journal clubs and continuing education events are used as vehicles to disseminate evidence and encourage practitioners to make changes to their practice. Although these activities can help raise awareness of new evidence, the methodology used to present the information may not meet everyone's needs, resulting in low rates of application. Recognizing the need for a clear map to illustrate how new evidence can be integrated into practice and to clarify the growing confusion that surrounds knowledge translation, Graham and others ${ }^{8}$ created the knowledge-toaction cycle. This framework identifies factors to

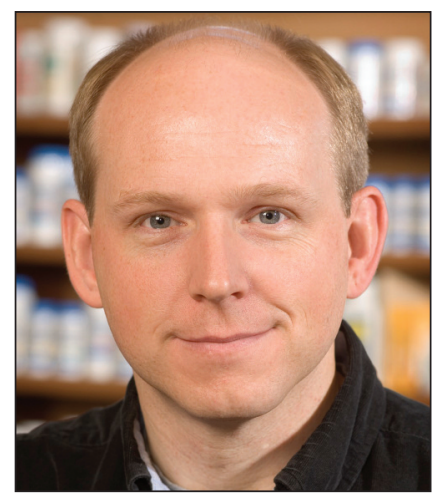
consider from the creation of new knowledge through to its application in practice. The 7 action phases of this framework are identifying the problem and the knowledge to be implemented, adapting or customizing the knowledge to the local context, assessing barriers and facilitators to knowledge use, identifying and tailoring the appropriate knowledge translation intervention, monitoring the use of knowledge, evaluating outcomes, and identifying strategies to support sustained knowledge use. ${ }^{8}$

Within the knowledge-to-action framework, an important phase is the assessment of potential barriers and facilitators to knowledge use. ${ }^{2}$ As knowledge users, we already know about the importance of critically appraising the source of any new information to ensure it is trustworthy. ${ }^{1}$ However, uptake of knowledge is influenced not only by the content and reliability of the information, but also by the practice setting and the individuals who are asked to integrate the knowledge into their practice. ${ }^{2,8}$ In other words, the way in which information is presented may be just as important as its content. A good understanding of the practice environment and characteristics of the individuals in the target audience will enable the creation of an effective message that facilitates application of knowledge. ${ }^{4}$

In this issue of the Canadian Journal of Hospital Pharmacy, Rosenthal and others ${ }^{9}$ describe an initiative to identify potential 
barriers and facilitators to knowledge use by learning about the current practice environment of hospital pharmacy. They used an Internet-based survey to reach hospital pharmacists across Canada and found that most respondents valued supportive factors, like teamwork and collaboration, and expressed achievement-oriented characteristics. The investigators also identified that environmental and individual characteristics varied significantly by region, level of respondent education, years of practice, and proportion of time spent performing clinical activities. These differences in practice environment and individual characteristics highlight the importance of change managers taking the time to learn the characteristics of their target audience.

As health care professionals, we have a responsibility to engage in lifelong learning and to continuously seek new information to help us provide good quality care to patients. Following the principles of evidence-based care, it is okay to be cautious of new interventions, because there certainly have been examples of "good ideas" that turned out to be wrong. ${ }^{10-12}$ When we do find good evidence to support a change in our practice, however, we also need to know how to share that information with our colleagues and encourage them to consider practice changes. Although the process of changing practice can be slow and challenging, 2,5 the knowledge-to-action cycle provides a framework that can help to effectively communicate new information and facilitate its application into practice. ${ }^{8}$ The goal of knowledge translation is to narrow the gap between evidence and practice, which will improve patient care, strengthen the health care system, and ultimately make us all better health care providers.

\section{References}

1. Guyatt G, Jaeschke R, Wilson MC, Montori VM, Richardson WS. What is evidence-based medicine? In: Guyatt G, Rennie D, Meade MO, Cook DJ, editors. Users' guides to the medical literature: a manual for evidence-based clinical practice. 3rd ed. New York (NY): McGraw-Hill; 2015. p. 7-14.

2. Grol R, Grimshaw J. From best evidence to best practice: effective implementation of change in patients' care. Lancet. 2003;362(9391):1225-30.

3. Institute of Medicine, Committee on Quality of Health Care in America. Crossing the quality chasm: a new health system for the 21st century. Washington (DC): National Academy Press; 2001. 337 p.
4. Davis D, Evans M, Jadad A, Perrier L, Rath D, Ryan D, et al. The case for knowledge translation: shortening the journey from evidence to effect. $B M J$. 2003;327(7405):33-5.

5. Morris ZS, Wooding S, Grant J. The answer is 17 years, what is the question: understanding time lags in translational research. J R Soc Med. 2011; 104(12):510-20.

6. About knowledge translation \& commercialization. Ottawa $(\mathrm{ON})$ : Canadian Institutes of Health Research; 2014 [cited 2015 Jan 15]. Available from: www.cihr-irsc.gc.ca/e/29418.html

7. Straus SE, Tetroe J, Graham ID. Knowledge translation: what it is and what it isn't. In: Straus SE, Tetroe J, Graham ID, editors. Knowledge translation in health care: moving from evidence to practice. Oxford (UK): Wiley Blackwell; 2013. p. 3-13.

8. Graham ID, Logan J, Harrison MB, Straus SE, Tetroe J, Caswell W, et al. Lost in knowledge translation: time for a map? J Contin Educ Health Prof. 2006;26(1):13-24.

9. Rosenthal M, Hall KW, Bussières JF, Tsuyuki RT. Professional culture and personality traits of hospital pharmacists across Canada: a fundamental first step in developing effective knowledge translation strategies. Can J Hosp Pharm. 2015;68(2):127-35.

10. Echt DS, Liebson PR, Mitchell LB, Peters RW, Obias-Manno D, Barker $\mathrm{AH}$, et al. Mortality and morbidity in patients receiving encainide, flecainide, or placebo. The Cardiac Arrhythmia Suppression Trial. $N$ Engl JMed. 1991;324(12):781-8.

11. Grady D, Herrington D, Bittner V, Blumenthal R, Davidson M, Hlatky M, et al.; HERS Research Group. Cardiovascular disease outcomes during 6.8 years of hormone therapy: Heart and Estrogen/progestin Replacement Study follow-up (HERS II). JAMA. 2002;288(1):49-57.

12. Bosch J, Yusuf S, Gerstein HC, Pogue J, Sheridan P, Dagenais G, et al. Effect of ramipril on the incidence of diabetes. N Engl J Med. 2006;355(15):1551-62

Scot H Simpson, BSP, PharmD, MSc, is with the Faculty of Pharmacy and Pharmaceutical Sciences, University of Alberta, Edmonton, Alberta. He is also an Associate Editor with the CJHP.

Competing interests: None declared.

Address correspondence to:

Dr Scot H Simpson

Faculty of Pharmacy and Pharmaceutical Sciences

3126 Dentistry / Pharmacy

University of Alberta

Edmonton AB T6G 2N8

e-mail : scot@ualberta.ca

\section{ON THE FRONT COVER}

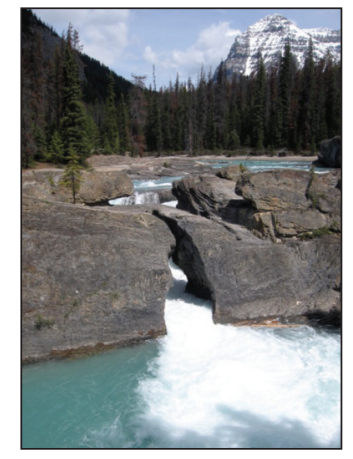

\section{Natural Bridge Yoho National Park, British Columbia}

CSHP member Natalie Garwah, of Timmins, Ontario, took this photograph of the Natural Bridge in Yoho National Park (near Field, British Columbia) on a sunny day in June 2011 during a family cross-country road trip. She captured the scene with a Canon PowerShot SD880 camera.

The CJHP would be pleased to consider photographs featuring Canadian scenery taken by CSHP members for use on the front cover of the journal. If you would like to submit a photograph, please send an electronic copy (minimum resolution $300 \mathrm{dpi}$ ) to cjhpedit@cshp.ca. 